\title{
Preparation of Calcium Melibionate
}

\author{
By William W. Walton and Horace S. Isbell
}

\begin{abstract}
It has been found possible to prepare the comparatively rare salt, calcium melibionate, in any desired quantity by electrolytic oxidation of a crude solution of melibiose. The melibiose solution, prepared from commercial raffinose, is subjected to electrolytic oxidation in the presence of calcium carbonate and calcium bromide, and the calcium melibionate is crystallized directly from the electrolyte. The optical rotation of a 2-percent aqueous solution of calcium melibionate, expressed on the anhydrous basis, was found to be $[\alpha]_{D}^{20}+$ $106.2^{\circ}$, which disagrees with the value, $[\alpha]_{D}^{17}+88.6^{\circ}$, reported in the literature. Calcium melibionate forms a basic calcium salt, $\mathrm{Ca}\left(\mathrm{C}_{12} \mathrm{H}_{21} \mathrm{O}_{12}\right)_{2} .4 \mathrm{CaO}$. This is analogous to the basic calcium salts of lactobionic and maltobionic acids.
\end{abstract}

\section{Introduction and Discussion}

The need for calcium melibionate in connection with a study of the glycosyl derivatives of ascorbic acid led to an investigation of methods available for its preparation. Neuberg, Scott, and Lachmann $[1]^{2}$ prepared calcium melibionate by oxidizing melibiose with bromine, removing the excess bromine with a stream of air, neutralizing with calcium carbonate, and separating the calcium melibionate from the accompanying calcium bromide by repeated crystallization from ethanol.

Levene and Wintersteiner [2] treated a solution of raffinose with baker's yeast and malt sprouts to obtain a crude solution of melibiose. This solution was purified by treatment with basic lead acetate, hydrogen sulfide, and a decolorizing carbon, and the melibiose in solution was oxidized with iodine in the presence of barium iodide and barium hydroxide. A lengthy purification of the melibionic acid involved the use of lead carbonate, sulfuric acid, silver sulfate, hydrogen sulfide, and barium hydroxide. The calcium salt was obtained by neutralization of the melibionic acid with calcium carbonate and crystallization from water by the addition of methanol.

\footnotetext{
1 The subject matter reported in this paper was abstracted from a thesis submitted by William W. Walton, of this Bureau, in June 1947 to the Faculty of the Graduate School of the University of Maryland, represented by Dr. Nathan L. Drake, in partial fulfillment of the requirements for the degree of Doctor of Philosophy. (See also J. Research NBS 41, 119 (1948) RP1910.)

${ }^{2}$ Figures in brackets indicate the literature references at the end of this paper.
}

Levene and Jorpes [3] obtained crystalline melibiose from raffinose and then oxidized the melibiose with bromine in the presence of barium benzoate [4]. They purified the melibionic acid by successive treatment with silver carbonate, hydrogen sulfide, sulfuric acid, and barium hydroxide, and finally by extraction of benzoic acid with chloroform. The solution of melibionic acid was boiled with calcium carbonate; the resulting calcium melibionate was precipitated by adding methanol and was recrystallized by dissolving in water and adding methanol.

The laborious purification steps required in all of these methods of preparation made desirable a simpler method for the preparation of calcium melibionate. Isbell and Frush [5] have developed a convenient method for the preparation of aldonic acids from aldoses by electrolytic oxidation. In the case of glucose, crude solutions can be oxidized and the acid separated directly from the electrolyte as the calcium salt. It seemed possible that calcium melibionate might be prepared by this method directly from the liquor that remained after hydrolysis of raffinose and fermentation of the resulting fructose.

Application of the electrolytic method to the preparation of calcium melibionate from melibiose and calcium carbonate gave a product that crystallized directly from the electrolyte as the reaction proceeded. The crystals were easily separated by filtration. By returning the mother liquor to the 
electrolytic cell with additional melibiose and calcium carbonate, the salt can be prepared in a continuous process similar to that used for the production of calcium gluconate [6]. The relatively small quantities of the salt required for the present study, however, were obtained in several separate preparations. The crude product was readily recrystallized from hot water.

Crystalline calcium melibionate is reported in the literature to contain from 11 to 15 percent of water. The product prepared by electrolytic oxidation varied in water content from 6.6 to 13.9 percent, and it was found that air-dried material lost or gained weight from day to day, apparently from changes in the relative humidity. An anhydrous sample gained more than 10 percent in weight when stored in a vacuum oven at $50^{\circ} \mathrm{C}$ but was restored to its anhydrous condition when dried in vacuum over anhydrous magnesium perchlorate at room temperature. The specific rotation, $[\alpha]_{D}^{20}$, of the pure salt in 2-percent aqueous solution was found to be $+106.2^{\circ}$, expressed on an anhydrous basis. The specific rotation is recorded in the literature as $+88.6^{\circ}$ at a temperature of $17^{\circ} \mathrm{C}$. Unfortunately, the wavelength of the light used is not given in the original publication [1], but the constant is quoted in various handbooks $[7,8]$ as $[\alpha]_{D}^{17}$.

Inasmuch as basic calcium salts are useful for the separation and purification of a number of sugar acids [9], it seemed desirable to ascertain whether melibionic acid also forms such a salt. The basic calcium salts of the monobasic acids derived from monosaccharides are of the type $\mathrm{Ca}$ (anion) ${ }_{2} .2 \mathrm{CaO}$. Two acids derived from disaccharides, lactobionic acid, and maltobionic acid, however, have yielded basic calcium salts having the formula $\mathrm{Ca}$ (anion) $)_{2} 4 \mathrm{CaO}$. A basic calcium salt of melibionic acid has now been prepared and found to have the composition $\mathrm{Ca}\left(\mathrm{C}_{12} \mathrm{H}_{21} \mathrm{O}_{12}\right)_{2} .4 \mathrm{CaO}$, which corresponds to the basic salts prepared from lactobionic and maltobionic acids. The new substance is difficultly soluble and useful for the preparation and purification of melibionic acid.

\section{Experimental Details}

\section{Preparation of a Solution of Melibiose}

Six hundred grams of raffinose (purity $99.08 \%$ based on optical rotation), equivalent to 1 mole of pure raffinose, was dissolved in 3.6 liters of water containing $60 \mathrm{ml}$ of nutrient solution. ${ }^{3}$ Four drops of a 1:1 aqueous acetic acid solution was added to bring the $\mathrm{pH}$ of the solution to 4.5 . The optical rotation of the solution was found to be $90.3^{\circ} \mathrm{S}(2-\mathrm{dm}$ tube). Twenty milliliters of invertase solution ${ }^{4}$ was added, and the mixture was allowed to stand at room temperature for 24 hr. The observed rotation, based on the volume before the addition of the invertase solution, was $47.8^{\circ} \mathrm{S}$ (2-dm tube). This value indicates that the sugar had been converted to melibiose and fructose to the extent of 97.4 percent.

To remove the fructose, two cakes of baker's yeast were added, and the solution was allowed to ferment for 3 days at room temperature. The optical rotation at the end of this period was $70.5^{\circ} \mathrm{S}$ (2-dm tube). For complete hydrolysis and destruction of the fructose, the calculated rotation should be $70.7^{\circ} \mathrm{S}$. The rotation obtained indicates that the conversion of the raffinose to melibiose and removal of the fructose was substantially quantitative.

The solution was heated to boiling to destroy the yeast, and clarified by the addition of $30 \mathrm{ml}$ of a decolorizing carbon, and filtration. The filtrate was concentrated under reduced pressure to 1.8 liters and used directly for the preparation of calcium melibionate.

\section{Preparation of Calcium Melibionate}

The solution of melibiose obtained from $600 \mathrm{~g}$ of raffinose was transferred to a 3-liter beaker, and $32 \mathrm{~g}$ of calcium bromide and $55 \mathrm{~g}$ of calcium carbonate were added. Two graphite electrodes, 22 $\mathrm{mm}$ in diameter, were immersed to a depth of 12 $\mathrm{cm}$, and the solution was stirred mechanically while a current of 1 ampere at $10.8 \mathrm{v}$ was passed through. The electrolysis was stopped when titration of an aliquot with iodine [10] indicated that 97.3 percent of the melibiose had been oxidized. The current efficiency was 82.9 percent. Higher current efficiencies were obtained for lower percentages of oxidation.

The solution was heated to dissolve the portion of the calcium melibionate that had crystallized, and the hot solution was filtered. The filtrate was concentrated under reduced pressure to a volume

\footnotetext{
3 The nutrient solution was made by dissolving $2.5 \mathrm{~g}$ of $\mathrm{NH}_{4} \mathrm{NO}_{3}, 0.3 \mathrm{~g}$ of $\mathrm{KH}_{2} \mathrm{PO}_{4}$, and $2.5 \mathrm{~g}$ of $\mathrm{MgSO}_{4} .7 \mathrm{H}_{2} \mathrm{O}$ in 1 liter of water.

4 The invertase solution is a commercial product made by Difco Laboratories, Detroit, Mich.
} 
of about $800 \mathrm{ml}$ and allowed to cool to room temperature. The calcium melibionate that crystallized from the solution was collected on a Büchner funnel and washed with three $25-\mathrm{ml}$ portions of cold water. Three hundred and twenty-five grams of crystalline calcium melibionate, calculated on the anhydrous basis, was obtained. The filtrate was concentrated under reduced pressure to 100 $\mathrm{ml}$, and $75 \mathrm{ml}$ of methanol was added. An additional crop of $40 \mathrm{~g}$ of calcium melibionate, calculated on the anhydrous basis, was obtained. The total yield of crude product was $365 \mathrm{~g}$ or 96.7 percent. Larger quantities of raffinose were used in a number of preparations without any difficulty.

For analysis, the crude material was recrystallized several times from hot water, and finally was air-dried. The water content of the material was determined by drying samples to constant weight at room temperature over anhydrous magnesium perchlorate, and the results reported below are expressed on the anhydrous basis.

Analysis: Calculated for anhydrous $\mathrm{Ca}\left(\mathrm{C}_{12} \mathrm{H}_{21^{-}}\right.$ $\left.\mathrm{O}_{12}\right)_{2}: \mathrm{Ca}, 5.31 ; \mathrm{C}, 38.2 ; \mathrm{H}, 5.6$. Found: $\mathrm{Ca}, 5.33$; C, 38.2; H, 5.7. $[\alpha]_{\mathrm{D}}^{20}=+106.2^{\circ}($ water, $\mathrm{c}=2)$.

\section{Preparation of Basic Calcium Melibionate, $\mathrm{Ca}\left(\mathrm{C}_{12} \mathrm{H}_{21} \mathrm{O}_{12}\right)_{2} .4 \mathrm{CaO}$}

Ten grams of calcium melibionate was dissolved in $200 \mathrm{ml}$ of water, and the solution was cooled to $0^{\circ} \mathrm{C}$. A suspension of $3.5 \mathrm{~g}$ of calcium oxide in $200 \mathrm{ml}$ of water at $0^{\circ} \mathrm{C}$. was added, and the mixture was shaken for several minutes. It was then filtered into a flask through which a current of carbon-dioxide-free air was passed. The clear solution was concentrated under reduced pressure to $150 \mathrm{ml}$ and finally heated for a few minutes on the steam bath to complete the precipitation of the basic salt. The salt was separated by filtration in the absence of carbon dioxide and dried at $60^{\circ} \mathrm{C}$ in vacuum. Analysis: Calculated for $\mathrm{Ca}\left(\mathrm{C}_{12} \mathrm{H}_{21} \mathrm{O}_{12}\right)_{2} .4 \mathrm{CaO}$ : total $\mathrm{Ca}, 20.47 ; \mathrm{CaO}, 22.91$. Found: total $\mathrm{Ca}, 20.45 ; \mathrm{CaO}, 22.56$.

The authors express their appreciation to Nancy B. Holt for the measurements of optical rotations and to Rolf A. Paulson for the determinations of carbon and hydrogen reported in this paper.

\section{References}

[1] C. Neuberg, L. Scott, and S. Lachmann, Biochem. Z. 24, 162 (1910).

[2] P. A. Levene and O. Wintersteiner, J. Biol. Chem. 75, 321 (1927).

[3] P. A. Levene and E. Jorpes, J. Biol. Chem. 86, 403 (1930).

[4] C. S. Hudson and H. S. Isbell, BS J. Research 3, 57 (1929) RP82.

[5] H. S. Isbell and H. L. Frush, BS J. Research 6, 1145 (1931) RP328.

[6] H. S. Isbell, H. L. Frush, and F. J. Bates, BS J. Research 8, 571 (1932) RP436.

[7] B. Tollens and H. Elsner, Kurzes Handbuch der Kohlenhydrate, p. 463 (Johann Ambrosius Barth, Leipzig, 1935).

[8] H. Vogel and A. Georg, Tabellen der Zucker un' Ihrer Derivate, p. 604 (Julius Springer, Berlin, 1931).

[9] H. S. Isbell and H. L. Frush, BS J. Research 11, 649 (1933) RP613.

[10] G. M. Kline and S. F. Acree, BS J. Research 5, 1063 (1930) RP247.

Washington, December 6, 1948. 